\title{
Liquid crystal chemistry and poetry
}

\author{
David Dunmur ${ }^{1}$
}

Accepted: 31 December 2020 / Published online: 17 January 2021

(c) The Author(s) 2021

\begin{abstract}
This paper comments on a recent article "Revolutionary poetry and liquid crystal chemistry: Herman Gorter, Ada Prins and the interface between literature and science" by Hub Zwart (Foundations of Chemistry, published online: 10 July 2020), in which the author explores the influence of the liquid crystal research of Ada Prins on the epic poem Pan written by her long-time lover Herman Gorter. The present paper reviews the basic science of liquid crystals and explains the connections between the work of Prins and its influence on the poem. Other examples of the use of "liquid crystal" as a literary device are identified from renaissance poetry, and the uses of the metaphor in these poems are analysed from a scientific perspective. From these examples it is suggested that creative concepts from poetry may contain elements of substance that appear in hitherto unrecognised scientific realities.
\end{abstract}

Keywords Liquid crystals · Chemistry $\cdot$ Chemistry and poetry $\cdot$ History of liquid crystals

\section{Introduction}

A recent paper by Hub Zwart (2020) has examined the relationship between the epic poetry of Netherlander Herman Gorter (1864-1927) and the scientific studies of his long-time lover Ada Prins (1879-1977), a liquid crystal chemist. Zwart claims that observations and concepts from science contributed by Gorter's muse provided inspiration for his magnum opus Pan, published initially in 1912, and then in full (Gorter 1916), a celebration of the "imminent proletarian revolution and the advent of the communist era" in which "science had become poetry (De Wetenschap was Poëzie geworden)".

Much of classical literature is allegorical or metaphorical, and the fables of the past sometimes carry visions of the future. The now ubiquitous genre of literature known as scifi pervades our culture, though it is a relatively recent invention. In English literature, Mary Shelley, famously though initially anonymously, used a brand of science to create life, while H G Wells explored many aspects of possible scientific developments which could impact dramatically on human existence on planet earth. Perhaps the most perspicacious

David Dunmur

d.dunmur@gmail.com

1 Emeritus Professor of Chemistry University of Sheffield, Christ Church, University of Oxford, Oxford, UK 
novel of Wells was "The World set Free" (Wells 1914) which anticipated by nearly half a century the development of nuclear energy and the atomic bomb, but it was Wells's "War of the Worlds" (Wells 1912) that created public panic when broadcast in the United Kingdom by the BBC. Science and scientific ideas pervade all types of literature and poetry, as usefully explored in "The Longman's Literary Companion to Science" (ed. Gratzer 1989), but one might reasonably ask to what extent, if any, does literature influence science: using the words of Gorter, "can poetry become science?".

This paper is a commentary on the article by Zwart, and provides further interpretation of the ideas from liquid crystal science used in the analysis of Gorter's Pan. Additionally the use of "liquid crystal" as a phrase in classical literature is explored, and other examples are given in which the concept of liquid crystal is used as a literary device rather than identified as a scientific phenomenon.

\section{The science of liquid crystals and liquid crystal chemistry}

Crystal is a noun which is applied to certain solid materials, while liquid may be a noun or an adjective which describes attributes of a fluid substance. Scientific terminology gives precise and detailed classifications of crystals, of which perhaps ice and diamonds will be the best known examples. Fluids or liquids are less easy to categorise and range from water to tar and lava flows, but science provides clear definitions of a crystal and a liquid as two of the three common states of matter, the third common state of matter is a gas. There can be transitions between different states of matter under the influence of changing temperature and/or pressure, as in the melting of ice to water and the boiling of liquid water to steam. But nature is never simple, and materials scientists now recognise that states of matter other than solid, liquid or gas can be identified and characterised: liquid crystal is one of these. The identification of this new state of matter at the end of the nineteenth century marked a significant development in our knowledge of the natural world. Ada Prins contributed to this landmark discovery, but her work has been overlooked in subsequent publications, and she has been ignored as a liquid crystal pioneer. The new state of matter, known as liquid crystal, was noticed when certain solid crystals on heating exhibited two melting points, one when the crystals disintegrated to an opaque fluid, and then at a higher temperature the fluid changed to a clear liquid. The opaque fluid intermediate on heating between the solid crystal and the clear liquid state has become known as the liquid crystal state of matter. As Zwart points out in his paper, the term liquid crystal is an oxymoron, a self-contradictory description, and there was much controversy over the initial discovery of the new phenomenon.

Ada Prins was carrying out her research into liquid crystals at a time when their existence was scarcely established in the scientific community. At the University of Amsterdam, Ada's research supervisor until his death in 1907 was Prof Hendrik Willem Bakhuis Roozeboom, a distinguished physical chemist, who was well aware of the controversy surrounding the identification of liquid crystals. In discussions of her work with Herman Gorter, Ada would have had the contemporary knowledge of the physical nature of liquid crystals, but at the time of the presentation of her thesis in 1908 (Prins 1908) there was no firmly established explanation or theory of the liquid crystalline state. So Gorter's conception and representation of liquid crystals through Ada's eyes and heart was perhaps as valid 
as the angry contradictory opinions exchanged by the leading liquid crystal scientists of the day.

In the poem Pan, Herman Gorter does not use the term "liquid crystal" explicitly, but the evidence presented by Zwart suggests that Ada Prins, his muse, science teacher and lover, was sharing her obsession for liquid crystals with Herman. At the time, the use of "crystal" to embrace "liquid crystal" would have been understandable, since it was the crystalline properties of the liquid crystals that set them apart from normal liquids. For Gorter, the term "crystal" captures the microscopic elemental nature of the material, but the importance of liquidity was that these crystal elements could become ordered and disordered under different circumstances to produce a bulk or macroscopic response through concerted action. Even more compelling for Gorter was the emphasis being placed by contemporary scientists upon the idea that liquid crystals were intermediate between inorganic (dead) and organic (living) materials: liquid crystals were "apparently living crystals." In the political story of Pan, the workers are the liquid crystals of society subject to external influences which may cause disorder, but also order through self-assembly and organisation, which ultimately would lead to the perfect communist utopia.

We do not know the political views of Ada Prins, but according to Zwart it was her scientific knowledge that provided a driving force for Gorter's poetic creativity. The optical properties of liquid crystals drew them to the attention of experimentalists, and it was the beautiful colours of liquid crystals that motivated Ada's research. The first material identified as a liquid crystal was the compound cholesteryl benzoate, discovered by botanist Friedrich Reinitzer (1888). He noted among other things that at the lower melting point of the compound there were flashes of blue and violet colours. Thanks to physicist Otto Lehmann (1889), the polarising microscope became the key experimental instrument for studying liquid crystals. Observers were amazed, and still are, by the stunning colourful images of liquid crystal droplets, and Lehmann painstakingly reproduced many of these images with pen and coloured inks. The variety of coloured images viewed under different circumstances all derive from the intrinsic structure of liquid crystals, and the colours exhibited can be related to the structure using the laws of physics (Dunmur and Sluckin 2011).

The interaction of light with different materials can be used as a probe of the nature and structure of matter, and x-ray crystallography can give a detailed picture of the arrangement of atoms in a solid crystal. However, as Zwart notes, x-rays had not been discovered when Ada Prins was carrying out her research. Light and x-rays are types of electro-magnetic radiation which is conveniently represented as a travelling wave, like a ripple on a pond, with a periodicity characterised by a wavelength which is the distance between successive wave peaks or troughs. The wavelength of x-rays is very short, a few ten-millionths of a millimetre, while visible light has wavelengths about a thousand times greater, typically half a micron (one thousandth of a millimetre) or about one hundred times smaller than the thickness of a human hair. If the wavelength of light (or x-rays) illuminating a sample corresponds to a structural regularity or periodicity in the material, a phenomenon known as diffraction occurs. The light is scattered to form a pattern of spots or lines from which the internal structure of the material can be deduced. The appearance of a diffraction pattern will depend crucially on the wavelength of the illuminating light, and from a light source of multiple wavelengths, as in white light, only particular wavelengths, or equivalently colours, will be scattered. Thus the colours of liquid crystals observed and admired by Ada were reflecting the intrinsic structure of the materials, but in a manner not understood at the time. A crucial point, of which acute experimentalists might have been aware at the beginning of the twentieth century, is that the coloured appearance of liquid crystals 
was a consequence of periodic structures in the materials that must have corresponded to the wavelengths of visible light. That is, distances at least a thousand times larger than atoms, but still much smaller than is visible in any sort of optical microscope, then or now. Ada was right to recognise the importance of the coloured appearance of liquid crystals.

Colour in substances arises in a number of ways. Chemical compounds in a material may absorb light of a particular colour (frequency or wavelength) from an illuminating source. Thus if a compound absorbs green light, it will appear red to an observer: this might be termed absorptive colour. Sometimes a source of colour may be a compound in the material which, while undergoing some chemical change, emits coloured light: this could be called luminescent colour. The colours from liquid crystals mostly occur through a different mechanism, which is the interaction between light and the structure of the material, as explained above, and this is termed diffractive or interference colour. A common example of this phenomenon is the coloured rainbow shown by a thin film of oil floating on water.

Returning to liquid crystals, the flashes of blue and violet light observed when liquid crystalline cholesteryl benzoate is solidified are actually due to the formation of complex spiral structures in the material which have a periodicity (repeat distance) equivalent to the wavelength of blue or violet light. Small changes in temperature change the repeat distance in the material and so the colour of the reflected light can change. The original phenomenon observed by Reinitzer in a bulk sample actually occurs because of the transient existence of a special type of liquid crystal known as a blue phase, but similar behaviour is shown by a variety of liquid crystals when prepared as thin films. The effect is known as "selective reflection", and occurs because light of a particular wavelength interacts with a structural periodicity in the material of a similar magnitude and the light of this wavelength (colour) is preferentially reflected. Indeed the effect has been widely used to produce cheap and effective liquid crystal thermometers, where the colour of the reflected light changes with temperature.

Following the intervention of Otto Lehmann in the liquid crystal story, the microscope became the important scientific tool with which to study liquid crystals. Lehmann's microscope was special in two respects. It was equipped with polarisers, that is, the object under view could be examined with polarised light. This could reveal features not immediately obvious in unpolarised light, but most importantly the provision of polarisers was necessary to view the interference and reflected colours exhibited by liquid crystal samples. The second vital feature was a heated sample holder (hot-stage) which enabled the liquid crystal to be heated and cooled, and corresponding changes with temperature viewed and recorded. The title of "Father of microscopy" is usually given to the Dutchman Anthonie van Leeuwenhoek (1632-1723), and it is reasonable to assume that the laboratory of Prof Roozeboom, Ada Prins's supervisor, would have had access to a microscope. So Ada would have been able to view and marvel at the coloured images of liquid crystals as they transformed and moved. Two images are provided that Ada might have seen: (1) the subtle changes as a liquid crystal sample is heated in a test tube, and: (2) a multi-coloured image of interference colours generated by a thin film of a liquid crystal viewed between crossed polarisers exhibiting many types of structure that can be observed for these remarkable materials (Figs. 1, 2).

What Ada and her contemporary scientist colleagues could not have anticipated was the huge impact that liquid crystals, and indirectly her own research, would have on the human race. The search for new cheap methods of transmitting information began in the 1930s, and television created a revolution. But the display was bulky, complicated and expensive to produce. New technologies for displays were investigated, and as early as 1934 the 

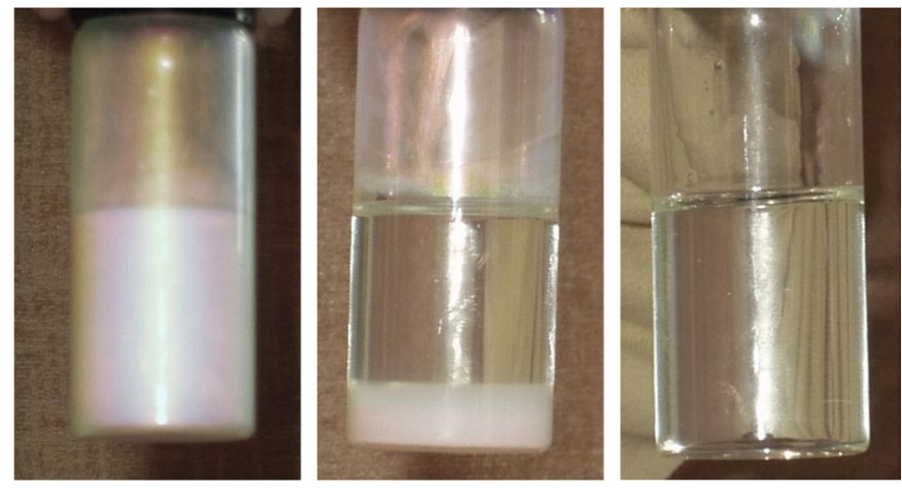

Fig. 1 A liquid crystal in a test-tube warmed from room temperature. On the left the liquid crystal is opalescent. On heating it changes to the clear liquid on the right. These pictures illustrate a liquid crystal to liquid transition

Fig. 2 A microscopic image of a thin film of a liquid crystal showing a variety of patterns and coloured regions which can be associated with different organisation within the sample

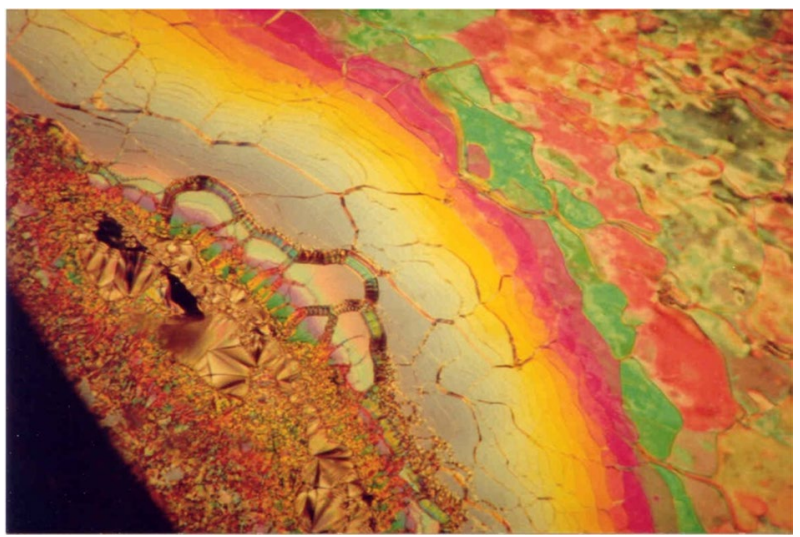

patent for an optical shutter using a liquid crystal was filed by the Marconi Company. However, it took another 40 years before the talents of chemists, physicists and electrical engineers created the flat screen liquid crystal display. So successful has it been that the number of LCDs on the planet exceeds the population.

\section{Liquid crystals in classical literature}

Zwart in his paper (Zwart 2020) refers to a possible anticipation of liquid crystals described by Edgar Allen Poe In his novel "The Narrative of Arthur Gordon Pym of Nantucket" (Poe 1838). In this tale, Poe wrote about an imagined island where streams flowed of a remarkable liquid which "... was not colourless, nor was it of any one uniform colour-presenting to the eye, as it flowed, every possible shade of purple, like the hues of a changeable silk." This account of the fictional stream has been interpreted (Stegemeyer and Kelker 1991) by scientists as a representation of a liquid crystal, though Poe never named it as such, and nor 
do flowing liquid crystals exist in nature. Poe did not, through remarkable foresight, anticipate the liquid crystals of the future.

Despite the oxymoronic nature of the term 'liquid crystal', the juxtaposition of these two words can conjure up a vision of a material with magical qualities. Indeed a modern account of the impact of liquid crystals on display technology has the title "Liquid Gold" (Castellano 2005), a clue to the fortunes made by some in the exploitation of these magic substances. So words can be used to carry information, even figuratively, but they can also be used like an artist's brush to create an impression. In this context, it is remarkable that there are instances of 'liquid crystal' being used by renaissance poets to create a new concept which embraces unexplained ideas or images. The reality of liquid crystal has been confirmed more than 500 years after the concept was introduced, and perhaps this can be claimed as "poetry becoming science".

Francesco Petrarca (1304-1374), Petrarch, was one of the key figures of the Italian Renaissance. Despite having a minor diplomatic position in the Catholic Church, Petrarch has become known as the "Father of Humanism". He has a huge legacy of writing, and has been widely studied and researched over the centuries. One of his lasting contributions to the Renaissance was to the development of a substantially new Italian language, and it is through this medium that the term 'liquidi cristalli' is first encountered, as far as we know. A major publication of Petrarch is his "Canzoniere", and it is in the first stanza of sonnet 219 that the reference to liquid crystals appears.

Il cantar novo e ' 1 pianger delli augelli

in sul di fanno retenir le valli,

e '1 mormorar de' liquidi cristalli

giú per lucidi, freschi rivi et snelli
At break of day the valley re-echoes

with the birds' fresh singing and lament, and the murmuring of liquid crystal

down the fresh, clear swift rivers

The English translation (Kline 2002) scarcely does justice to the original Italian, and we have no idea what Petrarch had in mind through his choice of liquidi cristalli. It is clear that the term refers to flowing, perhaps even the sound of flow, but the assumption must also be that the words are describing the appearance of the fluid. Another translation (Elliot 1993) echoes this.

\footnotetext{
The morning songs of birds on their sad themes

at daybreak fill the dene with echoing calls, and there's the sigh as liquid crystals fall, pouring in brisk and chilly shining streams
}

Without any additional explanation, readers are left to imagine the crystal-like image of the flowing stream, perhaps displaying transient colours as noted by Poe in his flight of fancy.

To compare our knowledge of liquid crystals with Petrarch's flash of inspiration is to speculate wildly. But the optical characteristics exhibited by liquid crystals do provide a special feature that causes liquids to appear like crystals. In the sonnet, 'mormorar' is used to describe a property of the flowing crystals, and here we have more difficulty. Liquid crystals, even flowing, do not generate sound, though from a physics point of view their acoustic properties are immensely complicated, and potentially very interesting. It is not impossible that the visco-elastic properties of liquid crystals could be responsible for the generation of sound under flow. It is known that liquid crystals of a particular type can 
detect sound waves and transform them to electrical signals, but the generation of sound by liquid crystals has not yet been investigated. It appears that Petrarch is opening up the reader's imagination in his sonnet 219 , but any influence on the discovery of Reinitzer can be discounted.

The Spanish poet Luis de Góngora y Argote (1561-1627) was greatly influenced by the work of Petrarch, though he lived and worked nearly two centuries later. Góngora knew Petrarch's work in detail, and perhaps it should not be a surprise that 'liquid crystal' appears in the poetry of Góngora, who is the acknowledged master of metaphor (Collins and Torres 2017). Such a reference appears in "The Solitudes I" (lines700-703), in Spanish of course, which is described as "the adventures of a shipwrecked pilgrim", though as a piece of literature Las Soledades is much more.

Estos árboles, pues, ve la mañana, mentir florestas y emular vials, cuantos muro de liquidos cristales agricultura urbana
The morning, then, sees these trees feigning forests emulating avenues enwalled in liquid crystal by farming most urbane

As is clear, the translation of Góngora's poems presents some challenges. The translation above is by Edith Grossman (Grossman 2011), but given below is another translation by the English Poet, Alastair Elliot (1932-2018) (private communication, 1995), which perhaps reveals a little more of Góngora's metaphor.

\footnotetext{
Next day the eye of morning sees pretended groves made of untruthful trees, avenues that the farming of their town has walled with liquid crystals and not stone
}

The scene described is a village that has been decorated for a fiesta, and is observed in the silence of the morning. The walls of the village (agricultura urbana) have been adorned with branches of trees described as liquid crystal. In metaphorical terms, perhaps this refers to the movement of the leaves and branches, rendering the harshness of the street as a mystical sylvan avenue.

There is another reference to liquid crystal in Góngora's Soledades I (lines 243-246), but used in a different sense.

Otra con ella montaraz zagala juntaba el cristal líquido al humano por el arcaduz bello de una mano que al uno menosprecia, al otro iguala
And by this mountain girl there was another, Who, to her human, liquid crystal gave; Her hand, sweet aqueduct for such a wave, Equalled the one but far outdid the other

This translation is also due to Edith Grossman (2011), the notes for which suggest that here liquid crystal is a metaphor for water.

\section{Poetic properties of liquid crystals}

To an experimental scientist there is nothing more poetic than the manifestation of the properties of liquid crystals. Indeed their optical images as viewed in a microscope have been used to create visual art (Leslie 2016), and many liquid crystal scientists will have such pictures decorating the walls of their offices or homes. Other properties of liquid crystals are equally remarkable, but less readily displayed. There is now a good understanding 
of many of the properties of liquid crystals, and their exceptional characteristics arise from fundamentals of their structure. Specifically, the order and disorder of the constituent molecules of the fluid and the extent of the local organisation of the structure determine the macroscopic behaviour of the material. These are the terms which Gorter understood and applied in his poem $P a n$.

Concepts of order and disorder are universal, but in applying them to materials, there is the issue of scale. What might appear to be superbly ordered on the outside, such as a well-built brick wall, may be internally disordered as in defective bricks, with ultimate consequences for the overall structure. The question of scale is especially important for liquid crystals, but less so for solid crystals. For the latter, modern techniques allow one to know in fine detail the arrangement of atoms in a crystal. For liquid crystals, the fundamental building blocks are molecules, which are organised in a particular fashion over a microscopic volume. But the structures are not static, the individual components are moving, and the whole ordered region can be in motion, hence the visual image often favoured by liquid crystal scientists of a shoal of fish: the fish being the molecules. For liquid crystals it is the component molecules that determine the local order and disorder of a sample, but the overall organisation of the local regions is determined by the preparation of the sample and the effects of containing surfaces and other external influences. The organisation of liquid crystal regions determine the bulk properties of the liquid crystal, and how it appears to an observer.

A distinguishing feature of liquid crystals, which has been included in the poetic metaphors, is motion or flow, and this is the liquid feature which changes the status of a crystal to something different. Dynamic phenomena in liquid crystals were detected in the earliest observations, and apparently mobile fluid droplets were seen to coalesce (copulate), which further added to their description as apparently living crystals. The dynamical properties of liquid crystals are complicated to describe, but they are crucial to our understanding of the liquid crystal state of matter.

The description of liquid crystals given above includes order and disorder and motion, but there are further qualities to add which are shape and direction. A brick has shape, and unlike a spherical object it appears different when viewed from different directions. In ordering bricks as in a wall, the orientation of the bricks is important. Generally they will be arranged parallel to each other, unless set in a pattern to represent a feature. The perceived ordered arrangement then depends on the position of the bricks and their orientation; disorder can be introduced through irregular positioning as well as changing their orientation in space. This picture translates perfectly to liquid crystals, except that the bricks (liquid crystal molecules) are also in motion. Introducing positional order and orientational order to states of matter, now allows a deeper understanding of liquid crystals. In simple terms a crystal can be defined as a structure having both positional and orientational order, while a liquid is characterised by positional disorder and orientational disorder; a liquid crystal is something in between, with positional disorder and orientational order. The latter does not necessarily require all the component elements to be aligned in the same direction, indeed there can be degrees of orientational disorder. However there must be sufficient orientational organisation in a liquid crystal to define a unique direction that represents the average alignment of the molecules. This is given a name "the director" and represents an average taken over perhaps tens of thousands of molecules. This quantity, the director, is a useful concept introduced to help in the mathematical representation of liquid crystals. The director has no real existence, so it is in some sense a metaphor, but it aids the description and understanding of liquid crystals. Thus the local structure of a liquid crystal 
may be associated with a director, but in a sample the director can change its orientation, and will be influenced by flow.

Liquid crystals are normally viewed in microscopes as thin films or droplets, and within these samples, the structure will adjust to the local order of the liquid crystal and the topology of the sample. Droplets of liquid crystal can be formed in various ways as freestanding drops, or suspended in a different liquid, or observed separating from a liquid crystal-forming fluid, and their shapes may be spherical, disc-like or spindle-like. These liquid crystal elements come closest to Gorter's metaphorical representation of workers, and combine the qualities of disorder and motion with the possibility of self-organisation.

\section{Discussion}

This paper, and the article it comments upon, are both inspired by the work of Ada Prins, a scientist from the University of Amsterdam and the first Dutch woman to be awarded a $\mathrm{PhD}$ in chemistry. The subject of her thesis was liquid crystal behaviour in mixtures, and at the time of Ada's studies (Prins 1909) this topic was at the forefront of research. Liquid crystals had been claimed as something new and interesting in 1888, but in the first decade of the twentieth century their nature and constitution were still far from resolved nor accepted by the scientific establishment. The impact of liquid crystal research on humankind through liquid crystal displays has already been mentioned, but it had long been recognised that this new state of matter has many potential applications. Even as Ada Prins was working on her PhD in 1907, the German chemical company E Merck from Darmstadt listed liquid crystals in its catalogue as "preparations for the demonstration of the properties of liquid crystals..." Early examples of liquid crystals only existed at elevated temperatures, but the preparation of mixtures was a way of lowering the temperature range of stability of these materials. In fact as further research has progressed and applications for liquid crystals have been discovered, it is always the formulation of mixtures that optimise the performance of these applications and enable them to function at ambient temperatures. But, far from being hailed as a pioneer in liquid crystal science, Ada Prins has been forgotten by science historians, and her work is largely unrecognised. According to Hub Zwart, it was through her personal life that the scientific research of Dr Prins has been immortalised in the poem Pan, written by her long-time lover, the giant of Dutch literature, Herman Gorter.

Current understanding of the science of liquid crystals illuminates Gorter's use of the liquid crystal metaphor. Its earlier appearances in poems by Petrarch and Góngora, centuries before the discovery of liquid crystals, show that the contradictory description of a material as a liquid crystal expands the range of imagery. It seems that Petrarch and Góngora focussed on the mobility of a fluid which had some of the visual characteristics of crystal, and this is now well-represented by the known physical properties of a liquid crystal. Gorter, by contrast, draws on the perceived or imagined inner structure of the liquid crystal. Perhaps this reflects a deep appreciation of the science by Gorter, and really does expose his close intellectual engagement with his muse and teacher, the chemist Ada Prins. The modern understanding of liquid crystals has to include the notion of order and partial order and disorder. A fundamental law of thermodynamics, Nernst's Third Law, informs that perfect order is only possible at the lowest of all temperatures, absolute zero, and in that state nothing can happen-a system is dead. For something to be responsive to internal 
or external stimuli it must have some disorder. From a scientific perspective, liquid crystals are more liquid than crystal.

The imagery used by Gorter in the poem Pan has a sophistication that goes beyond the accepted level of scientific knowledge of liquid crystals at the time, and so the poet is using his intuition to extend the metaphor to his description of social revolution. On the other hand, the metaphoric uses of liquid crystal by Petrarch and Góngora have no scientific underpinning, which indicate that these poets had a mental vision of a state between crystal and fluid yet to be revealed. This suggests that the transfer of imagery between science and art, poetry in this case, can be a two-way process, and as Gorter maintains, science can become poetry and poetry can become science.

Author contributions This paper is solely the result of the author's work.

Funding This paper is not the outcome of a funded or supported project.

\section{Compliance with ethical standards}

Conflict of interest There are no conflicts of interest.

Open Access This article is licensed under a Creative Commons Attribution 4.0 International License, which permits use, sharing, adaptation, distribution and reproduction in any medium or format, as long as you give appropriate credit to the original author(s) and the source, provide a link to the Creative Commons licence, and indicate if changes were made. The images or other third party material in this article are included in the article's Creative Commons licence, unless indicated otherwise in a credit line to the material. If material is not included in the article's Creative Commons licence and your intended use is not permitted by statutory regulation or exceeds the permitted use, you will need to obtain permission directly from the copyright holder. To view a copy of this licence, visit http://creativecommons.org/licenses/by/4.0/.

\section{References}

Castellano, J.A.: Liquid Gold. World Scientific, Singapore (2005)

Collins, M.S., Torres, I.: Metaphor and matter(s) arising: Gongorine metaphor and the cultivation of the imagination. Bull. Span. Stud. XCIII(7 \& 8), 1129-1156 (2017). https://doi.org/10.1080/14753 820.2016.1219506

Dunmur, D., Sluckin, T.: Soap, Science, and Flat-Screen TVs: A History of Liquid Crystals. Oxford University Press, Oxford (2011)

Elliot, A.: Italian Landscape Poems, p. 17. Bloodaxe Books, Newcastle upon Tyne (1993)

Gorter, H.: Pan: een gedicht. Versluys, Amsterdam (1916)

Gratzer, W. (ed.): The Longman Literary Companion to Science. Longman, Harlow (1989)

Grossman, E.: The Solitudes by Luis Góngora. Penguin Books, London (2011)

Kline, A.S.: Petrach the complete canzoniere. Poetry in translation. www.poetryintranslation.com (2002). Accessed 2 Aug 2020

Lehmann, O.: Über fliessende Krystalle. Z. Phys. Chem. 4, 462-472 (1889)

Leslie, E.: Liquid Crystals: the Science and Art of a Fluid Form. Reaktion Books, London (2016)

Poe, E.A: The Narrative of Arthur Gordon Pym of Nantucket, Oxford University Press, New York (1994). First published 1838 Harper and Brothers New York

Prins, A.: Vloeiende mengkristallen bij binaire stelsels. De Bussy, Amsterdam (1908)

Prins, A.: Flüssige Mischkristalle in binären Systemen. Z. Phys. Chem. 67(1), 689-723 (1909)

Reinitzer, F.: Beiträge zur Kenntnis des Cholesterins. Monat. Chem. (Wien) 9, 421-441 (1888)

Stegemeyer, H., Kelker, H.: Cholesterics already described in 1838. Liq. Cryst. Today 1(2), 3 (1991)

Wells, H.G.: The war of the worlds. Heinemann, London (1912)

Wells, H.G.: The world set free. Hogarth, London (1914) 
Zwart, H.: Revolutionary poetry and liquid crystal chemistry: Herman Gorter, Ada Prins and the interface between literature and science. Found Chem. https://ezproxy-prd.bodleian.ox.ac.uk:2102/10.1007/ s10698-020-09381-5 (2020). Accessed 13 July 2020

Publisher's Note Springer Nature remains neutral with regard to jurisdictional claims in published maps and institutional affiliations. 